\title{
Letramento Gráfico: Perspectivas Presentes nos PCNEM e Ações no Ensino de Química
}

\section{Graphical Literacy: Perspectives Found in PCNEM and Actions in Chemistry Teaching}

\author{
Mikeas S. de Lima e Salete L. Queiroz
}

Resumo: O conceito de letramento gráfico (LG) se constitui como o conhecimento para lidar com os modos de comunicação visual. No contexto do ensino de ciências o LG está fortemente associado ao trabalho com as inscrições, que são representações materiais, tais como gráficos, fotografias, mapas e tabelas, elaborados para retratar os objetos e fenômenos de estudo da ciência. Dada a importância das inscrições para o ensino de ciências, o fato de estudantes apresentarem dificuldades no seu uso e interpretação é preocupante. O presente trabalho investigou, a partir da análise de conteúdo, o teor de menções ao LG nos Parâmetros Curriculares Nacionais do Ensino Médio (PCNEM) e como as recomendações neles expostas vêm sendo atendidas em ambientes de ensino de química. O segundo propósito foi alcançado tomando como objeto de estudo os artigos publicados na seção "Relatos de Sala de Aula" desta revista, desde o seu início até 2017, a partir da identificação de solicitações aos alunos de ações que remetem ao LG. Em relação aos PCNEM, foram encontradas menções que exemplificam o uso de inscrições em sala de aula e que apontam habilidades que os alunos devem desenvolver, possibilitando o LG. Na referida seção foram localizados apenas 33 artigos contendo o tipo de solicitação mencionada, de um total de 129, sugerindo que práticas que fomentam o LG em aulas de química ainda são escassas no contexto nacional. Estas estão associadas principalmente à produção de desenhos e uso de fotografias e tabelas, com poucos pedidos de uso ou produção de gráficos.

Palavras-chave: Letramento Gráfico. PCNEM. QNEsc.

\begin{abstract}
The concept of graphical literacy (GL) is defined as the knowledge to deal with different visual communication formats. In the context of science education, GL is strongly associated to work with inscriptions, which are material representations, such as graphs, photographs, maps, and tables, designed to portray objects and phenomena of the study of science. Given the importance of inscriptions for science teaching, the fact that students find it challenging to use and interpret them is a matter of concern. Based on content analysis, this study investigated the content of references to GL in the Parâmetros Curriculares Nacionais do Ensino Médio (PCNEM) and how the recommendations are seen being implemented in chemistry teaching environments. The sub aim was to study the articles published in the section Relatos de Sala de Aula of this journal from the beginning until 2017, based on identifying requests to students of actions that refer to GL. Concerning PCNEM, references were found that exemplify the use of inscriptions in the classroom and that point out skills that students should develop and that make GL possible. In this section, only 33 articles containing the type of request mentioned were found out of a total of 129 , showing that practices that promote GL in chemistry classes are still scarce in the national context. These are mainly associated to drawings and the use of photographs and tables, with few requests for using graphics.
\end{abstract}

Keywords: Graphical Literacy. PCNEM. QNEsc.

Mikeas Silva de Lima (qmikeas@ usp.br), licenciado em Química pela Universidade Federal da Paraíba (UFPB), é mestre em Química pelo Instituto de Química de São Carlos (IQSC) da Universidade de São Paulo (USP). São Carlos, SP - BR. Salete Linhares Queiroz (salete @iqsc.usp.br) é doutora em Química pela Unesp e professora do IQSC/USP, onde coordena o GPEQSC. São Carlos, SP - BR.

Recebido em 05/08/2018, aceito em 25/03/2019

A seção "Cadernos de Pesquisa" é um espaço dedicado exclusivamente para artigos inéditos (empíricos, de revisão ou teóricos) que apresentem profundidade teórico-metodológica, gerem conhecimentos novos para a área e contribuições para o avanço da pesquisa em Ensino de Química. 
Em um mundo em que o tempo é considerado curto e as informações veiculadas estão se tornando cada vez mais complexas, o emprego de representações, tais como fotografias, gráficos, desenhos, entre outros, é reconhecido pelas suas possibilidades e potencialidades. E, seguindo o movimento mundial de integração tecnológica, de crescimento da sociedade e do uso da internet, somos progressivamente expostos e nos tornamos dele dependentes.

Inclusive a própria ciência se desenvolveu a partir do uso de ilustrações, diagramas, gráficos, entre outras representações não-textuais, por filósofos naturalistas na representação dos objetos e fenômenos investigados (Lunsford et al., 2007). De forma que, atualmente, gráficos se constituem em uma vital forma de apresentação e comunicação de dados e informações utilizadas pelos cientistas. Isso advém da facilidade que estes possuem em demonstrar relações, padrões, tendências e variações. Tais aspectos são difíceis de serem enxergados na visualização direta do fenômeno, ou descritos por meio da linguagem verbal.

No contexto do presente trabalho, adotamos a perspectiva de Latour e Woolgar (1997) e assumimos o termo inscrição para nomear, antropologicamente e sociologicamente, representações visuais materiais, tais como gráficos, fotografias, mapas e tabelas, inerentemente elaborados para retratar os objetos e fenômenos de estudo da ciência. Tais ferramentas culturais, na comunidade científica, são empregadas como evidências às conclusões, assim como matéria-prima para a elaboração de justificativas, modelos e argumentos.

O uso de inscrições é central na produção científica, já que elas podem ser transformadas, rotuladas, superpostas e simplificadas, permitindo facilmente a inclusão, como uma base de evidência, em artigos de pesquisa. Segundo Latour e Woolgar (1997), a criação e a produção de inscrição são ferramentas cognitivas e psicomotoras para vários processos científicos, desde a coleta até a análise e apresentação dos dados. As inscrições também multiplicam e recriam os sentidos nos dados apresentados, os quais não seriam percebidos de outra forma (Lemke, 1998).

A expressão letramento gráfico deriva de diversos termos, como graphical literacy, graphicacy ou graph sense, entre outros, em inglês, que se referem, segundo Roth et al. (2005), ao conhecimento relativo que os estudantes devem desenvolver para que possam lidar diariamente com os modos de comunicação visual, em especial as inscrições. Numa visão mais ampla, o letramento gráfico, além de proporcionar uma leitura eficiente de inscrições, permite ao aluno questionar as relações de poder construídas, assim como os discursos e identidades produzidas e reproduzidas na utilização das várias formas de representação gráfica dos fenômenos estudados pela ciência (Roth et al., 2005). É necessário destacar que o termo letramento gráfico encontra correspondência em alguns trabalhos brasileiros de ensino de química, a partir do termo letramento visual (Ferreira e Arroio, 2013). Porém, este último apresenta uma perspectiva mais ampla, já que considera o estudo de imagens estáticas, em movimentos e mistas, como por exemplo, vídeos, animações e até mesmo gestos realizados por um locutor durante o processo de comunicação. O letramento visual transcende ainda a área do ensino de ciências. Já o letramento gráfico, na perspectiva de Roth et al. (2005), se preocupa apenas com as inscrições, em suas formas bidimensionais, e a relação icônica que estas estabelecem com o mundo dos fenômenos e objetos.

Dada a importância das inscrições, tanto para a ciência, quanto para o ensino de ciências, assim como a sua forte presença em livros didáticos, periódicos e salas de aulas, entre outros, o fato de diversos estudantes apresentarem dificuldades no seu uso e interpretação é inquietante. A partir disso, e com o advento da cultura visual, não é surpreendente que educadores venham chamando atenção para que haja uma correta orientação em como ler, interpretar e avaliar as inscrições e informações às quais os indivíduos são expostos.

As pesquisas que vêm sendo realizadas sobre a temática geralmente destacam dois aspectos. O primeiro é o nível e os fatores que influenciam a compreensão das inscrições pelos alunos (Silva, 2015; Bowen e Roth, 2002), que indicam problemas em sua apresentação durante as aulas e nos livros didáticos. Tal fator impulsiona o segundo aspecto de pesquisa com inscrições: a análise semiótica daquelas presentes nos livros didáticos, em artigos científicos, entre outros meios (Xavier, 2015; Pozzer e Roth, 2003), revelando quais são os processos mentais que os alunos precisam realizar para interpretá-las. Porém, abordagens sobre a forma como as práticas de inscrições devem permear as salas de aulas de ciências, em especial, as salas brasileiras, são escassas.

Nesse contexto, destacamos a dissertação de mestrado de Araujo (2008), que analisou as recomendações quanto ao uso de gráficos e tabelas, nos Parâmetros Curriculares Nacionais do Ensino Fundamental (Brasil, 1997), com foco na disciplina de matemática, no bloco "Tratamento de Informações". Segundo o autor, diversas partes do documento denotam a importância do uso de gráficos e tabelas durante esse nível de ensino, assim como também a relevância da produção textual a partir da interpretação de representações gráficas extraídas de textos jornalísticos e científicos, ou seja, abrindo espaço para a interdisciplinaridade.

Tendo em vista a importância das inscrições na ciência e a necessidade de um trabalho sistemático com essas práticas em sala de aula, o presente artigo tem como objetivo inicial analisar os Parâmetros Curriculares Nacionais do Ensino Médio - PCNEM (Brasil, 1999a), com o intuito de verificar a recorrência e o teor das menções acerca das atividades de letramento gráfico e da compreensão de gráficos nesse documento. A Base Nacional Comum Curricular (Brasil, 2017), apesar de ser um documento atual, não contempla ainda o ensino médio, portanto não entrou em nossas discussões. A atual versão das Diretrizes Curriculares Nacionais para o Ensino Médio (DCNEM) (Brasil, 2012) também não foi considerada para as discussões, pois análises prévias revelaram pouca recorrência 
do tema abordado nesse documento. De fato, só foi possível encontrar duas menções nas DCNEM, a saber:

$\S 4^{\circ}$ A cultura é conceituada como o processo de produção de expressões materiais, símbolos, representações e significados que correspondem a valores éticos, políticos e estéticos que orientam as normas de conduta de uma sociedade (Brasil, 2012, p. 2, grifo nosso).

Com o objetivo de também investigar como as demandas e recomendações encontradas nos PCNEM vêm sendo atendidas em ambientes de ensino de química, neste trabalho foram identificadas ações que remetem à questão do letramento gráfico, mencionadas em artigos publicados na revista Química Nova na Escola (QNEsc). Embora existam várias seções nas quais o letramento gráfico pode ser abordado, selecionou-se a seção "Relatos de Sala de Aula", visto que esta é a que tem objetivo primordial de reportar experiências do professor em sala de aula. Nessa perspectiva, nos juntamos ao rol daqueles pesquisadores que utilizam artigos da referida revista para procurar identificar alguma regularidade em situações de ensino, à exemplo do que foi realizado por Queiroz e Veras (2015), que verificaram as menções à QNEsc em artigos publicados nela mesma, a fim de constatar suas contribuições para o desenvolvimento de atividades didáticas.

Com base no exposto, este artigo tem potencialidade para contribuir para a realização de um trabalho mais sistemático com inscrições em aulas de química, assim como fomentar as discussões sobre essas práticas nos espaços formativos docentes.

\section{Letramento Gráfico}

Como mencionado anteriormente, o letramento gráfico representa o conhecimento que os alunos necessitam para lidar com as inscrições. Pensando-se no próprio alfabeto, quando criado, cada letra era considerada uma imagem, ou seja, não havia distinção entre letras e imagens: o letramento e o letramento gráfico estavam fundidos. Construir uma sentença era apenas colocar imagens em uma ordem que fizesse sentido (Danos, 2011). Com o surgimento da impressão, os textos e as ilustrações se diferenciaram, mas os modos verbais de comunicação (escrita e fala) foram considerados superiores nas práticas comunicativas, resultando que figuras, gráficos, entre outros modos visuais de comunicação, eram utilizados principalmente de maneira ilustrativa (Danos, 2011).

No entanto, questionar o papel atribuído a esses modos é, além de indispensável, autêntico e legítimo para a compreensão em uma dimensão mais ampla do fenômeno de comunicação, em especial, a comunicação científica, já que letramento e letramento matemático não são mais suficientes para se comunicar efetivamente. Habilidades adicionais de manuseio de representações gráficas, que representam o desenvolvimento do letramento gráfico, também são necessárias aos estudantes (Stokes, 2002).

Algumas habilidades referentes ao desenvolvimento do letramento gráfico listadas na literatura são: ler, interpretar, produzir inscrições; traduzi-las entre si; adequá-las a situações diferentes daquelas em que foram concebidas; reconhecer que elas não representam, em sua totalidade, a realidade; aplicar recursos semióticos e ferramentas matemáticas para direcionar a produção de sentidos; interagir com a inscrição, de forma a manipulá-la mentalmente e concretamente; extrapolar, prever e inferir relações entre os dados nela presentes; questionar e refletir sobre a forma como tal representação foi construída, entre outras (Roth et al., 2005; Olande, 2014).

Acerca da habilidade e do processo de ler e interpretar inscrições, este não é tão simples. O processo de desconstrução da inscrição, ou seja, o acesso à intenção do autor e à recuperação da realidade transmitida na inscrição é uma das maiores dificuldades encontradas pelos estudantes durante o manuseio das mesmas. Segundo Roth (2002), as análises e pesquisas acerca da leitura e interpretação de gráficos têm sido conduzidas a partir de duas ênfases, que podem representar as fontes de problemas durante o trabalho com inscrições. A primeira trata de uma aproximação que toma como pontos de partidas ontológicos as habilidades dos estudantes e as qualidades dos gráficos apresentados nos textos didáticos e na sala de aula. A segunda aproximação se concentra no papel da cultura e das experiências individuais no entendimento das inscrições, descrevendo seu uso como uma prática social.

Em relação à primeira aproximação, as análises da interação dos alunos com as inscrições presentes no livro didático e em ambientes de ensino fornecem uma base para discutir as suas competências em diversas práticas científicas, incluindo as de uso e interpretação de inscrições, já que essas são as fontes primárias de encontro dos estudantes de ciências com as inscrições. As pesquisas nessa abordagem ainda revelam grandes problemas na forma como estas são apresentadas nos textos ou durante as aulas, tais como a falta de elementos informativos (legendas e rótulos) nas inscrições, recorrente uso destas apenas com função ilustrativa etc.

Nass (2008) analisa os gráficos cartesianos presentes em livros didáticos brasileiros destinados ao ensino de química, publicados entre 2001 e 2006. O autor verificou que muitos gráficos continham deficiências estruturais, como a falta de elementos informativos (legendas e rótulos), e até mesmo falta de escala; a maioria dos gráficos possuía apenas uma função ilustrativa, o que fomenta a perpetuação do pensamento de que estudar química significa memorizar fórmulas; a inclusão dos gráficos nos textos didáticos se dava quando os autores acreditavam que a inscrição explicaria o fenômeno em estudo de uma forma melhor que as palavras, porém, esqueciam que para o aluno interpretar corretamente um gráfico é preciso estar familiarizado com ele. 
Nessa perspectiva, Roth et al. (2005) recomendam que os autores de inscrições devem atentar para as características da inscrição criada, assim como para a sua inclusão no texto principal. Por exemplo, em um gráfico, incluir legendas e rótulos, observar o esquema de cores e tamanhos de linhas, entre outros aspectos; em uma fotografia, observar o foco da imagem, a iluminação e a perspectiva. Para os autores, esses aspectos, juntamente ao texto escrito, são usados como marcadores, que permitem aos leitores coordenar a orientação da leitura para a produção adequada de sentidos, reduzindo e limitando a flexibilidade interpretativa das inscrições. Em relação a isso, Nass (2008) concorda com as recomendações anteriores e adiciona que os autores de livros didáticos devem abordar os aspectos sociais do gráfico, como o seu contexto de produção e aplicação, dando utilidade ao conhecimento apresentado na inscrição e, assim, conquistando a confiança do aluno e proporcionando um contínuo amadurecimento do seu letramento gráfico.

O segundo tipo de aproximação realizada nas pesquisas com leitura e interpretação de gráficos evidencia que as dificuldades apresentadas nesses processos advêm da falta de familiaridade do aluno com as práticas e atividades que envolvem inscrições, ou seja, existem lacunas de experiências participativas em práticas sociais, históricas e culturais de uso de inscrições. Essa perspectiva traz o desenvolvimento do letramento gráfico, por meio da interação com as inscrições, como uma prática social. Roth et al. (2005) identificam que as inscrições são frequentemente consideradas como independentes do contexto, como se tivessem sentidos por si só. Porém, com base na semiótica social, os possíveis sentidos transmitidos em uma inscrição não são propriedades delas, mas dependem do contexto social em que estão inseridas, assim, tais sentidos estão sempre abertos à reconstrução.

Para Roth et al. (2005), tomar as inscrições como práticas sociais revela os melhores caminhos (práticas) para trabalhar a leitura de inscrições e o desenvolvimento de letramento gráfico a partir do uso de textos científicos e didáticos na sala de aula. Tais caminhos emergem da interação entre os membros de uma sociedade e as produções que essas interações elaboram. Como exemplo disso, na comunidade científica, temos a redação de um artigo ou de um relatório, a produção de uma exposição oral, a apresentação de um pôster etc. Essas práticas são consideradas pelos autores como as práticas de ordem superior que estão disponíveis aos membros daquela comunidade, para o trabalho com as inscrições.

Assim, dificuldades em interpretação e compreensão de inscrições não devem ser visualizadas como um indício de deficiência cognitiva, mas, primeiramente, deve-se verificar as características visuais da inscrição, e em seguida, a falta de experiências, familiaridade e conhecimentos prévios do indivíduo com o tema e com práticas que põe em evidência atividades de leitura, interpretação, transformação e criação de inscrições. Tais atividades, que representam muito mais do que apenas a exposição dos estudantes às inscrições, fazem com que percebam a importância e os propósitos destas.

Para Roth e McGinn (1998), as inscrições poderiam ser incluídas no ensino de ciências a partir de abordagens práticas e autênticas, de forma que os estudantes entendessem que a habilidade de se comunicar via inscrições não é apenas construir gráficos e tabelas a partir de um conjunto de dados. Quando inseridos em uma sequência de processos, que os levem a pensar em termos de inscrições, a natureza e o propósito delas para a ciência tornam-se mais claros, facilitando a sua criação e compreensão.

Sendo assim, o professor apresenta um papel importante, pois, por se configurar como uma linguagem, a representação gráfica, sua leitura e interpretação, precisam ser ensinadas. O acesso à compreensão e ao emprego efetivo de inscrições pelos estudantes se dá por meio da adoção de práticas mediadas por inscrições na sala de aula. Ou seja, é necessário que sejam criados ambientes de aprendizagem que ajudem os estudantes a se tornarem letrados em práticas de inscrições. O letramento gráfico deve ser visto e tratado a partir da organização do currículo em práticas epistemológicas que permitam a emancipação do estudante, a partir do engajamento em questionamentos acerca do uso das inscrições, assim como desenvolvimento de competências em práticas científicas de representações gráficas e de níveis de letramento gráfico (Roth et al., 2005).

Mas para que essas atividades e abordagens sejam aplicadas de forma coerente e que resultem no desenvolvimento de habilidades com o uso de inscrições pelos alunos, professores de ciências precisam estar devidamente preparados, tanto em conhecimento sobre as práticas aqui discutidas, quanto em metodologias de ensino. Assim, a inclusão dessas discussões e também dessas práticas nos cursos de formação docente se fazem necessárias, para que os futuros professores estejam mais capacitados a construírem, lerem, interpretarem e discutirem inscrições, entre outras formas de representação do conhecimento científico, assim como para terem a capacidade de desenvolver essas habilidades nos seus alunos, não apenas por meio da exposição dos mesmos às inscrições, mas sim por tarefas e atividades que incorporem experiências autenticamente científicas.

\section{Percurso Metodológico}

A presente investigação envolveu duas etapas. A primeira se caracteriza como análise de conteúdo (Bardin, 2009) das seguintes partes do PCNEM: Parte I/Bases Legais (Brasil, 1999a) e Parte III/Ciências da Natureza, Matemática e suas Tecnologias (Brasil, 1999b).

Inicialmente, foram definidas as unidades de registro, ou seja, "o elemento unitário de conteúdo a ser submetido posteriormente à classificação" (Moraes, 1999). A partir de uma leitura superficial dos documentos, foram selecionadas cinco unidades de registro que fazem menção às atividades (práticas 
de inscrições) de letramento gráfico no processo educativo: gráfic', símbol', representaç', visual' e image'. O apóstrofo visa capturar possíveis flexões de gênero, número (por exemplo, gráfica, gráficos), entre outras, que possam ocorrer a partir da unidade de registro.

A seguir, cada unidade de registro foi isolada a fim de identificar as unidades de contexto, que servem de referência às unidades de registro, fixando limites contextuais para interpretá-la (Moraes, 1999), para posterior categorização dessas unidades, a partir do agrupamento de unidades que possuíam temática em comum. Uma leitura completa e aprofundada dos documentos proporcionou a identificação das categorias, assim como concepções implícitas, disponíveis na construção de ideias no texto. Tais categorias foram discutidas com base nos trabalhos de Roth et al. (2005).

A segunda etapa de análise consistiu em um levantamento dos artigos da seção "Relatos de Sala de Aula" da revista QNEsc, no período 1995 a 2017, tendo em vista a identificação de relatos que trouxessem em seu bojo práticas que colocavam os alunos em contato com as inscrições, ou seja, que continham potencial para desenvolvimento de letramento gráfico. Para tanto, realizou-se novamente uma análise de conteúdo (Bardin, 2009), tendo sido lidos os títulos, resumos, e palavras-chave dos artigos, assim como as sequências didáticas (SD) aplicadas durante as experiências neles relatadas, procurando nos artigos palavras que faziam referência ao uso de inscrições, tais como desenh', tabela, mapa, gráfico, foto' e image'. Em seguida, os artigos selecionados na etapa anterior foram lidos na íntegra, categorizados e discutidos.

\section{Letramento Gráfico nos PCNEM}

Os resultados expressos na Tabela 1 demonstram a frequência das unidades de registro nos PCNEM. As unidades de registro que não estavam de acordo com a temática das inscrições foram desconsideradas, como por exemplo, a palavra "bibliográfica".

A Parte III dos PCNEM, que versa sobre o ensino das ciências da natureza, matemática e suas tecnologias, apresenta uma frequência das unidades de registro muito maior que a Parte I, mesmo com uma grande diferença entre a quantidade de páginas entre esses documentos: a Parte I dos PCNEM contém 109 páginas e a Parte III, 58 páginas. As Bases Legais não têm pretensão explícita de tratar sobre as ciências. Seu conteúdo é direcionado tanto ao ensino de ciências e matemáticas, assim como ao ensino de linguagens e de ciências humanas. E já que as inscrições constituem um dos aspectos centrais das ciências da natureza não é surpresa que uma quantidade maior de unidades de registros seja encontrada na Parte III.

Em 1999, quando a Parte I foi escrita, a cultura visual ainda não havia emergido fortemente, o que pode justificar também a baixa frequência de menções às práticas de inscrições nesse documento. No entanto, nos dias atuais é relevante uma educação que trate da cultura visual e fomente nos alunos senso crítico para avaliar as inscrições. Considerando que as DCNEM sofreram uma recente atualização em 2012, a pouca recorrência dessa temática nesse documento revela certo descuido, que poderá trazer consequências também para as ciências humanas e para as linguagens, uma vez que as inscrições apresentam um caráter interdisciplinar, sendo utilizadas em outras áreas para produção de conhecimento.

Com as unidades de registro quantificadas corretamente, foram identificadas duas categorias: "Habilidades relacionadas ao uso de inscrições" e "Uso de inscrições". A primeira categoria inclui as menções às habilidades que os alunos devem desenvolver que possibilitem o letramento gráfico e o uso de inscrições; e a segunda categoria inclui as menções que exemplificam o uso de inscrições na sala de aula. A maioria das unidades de registro, 34 no total, está relacionada à categoria "Habilidades relacionadas ao uso de inscrições". Na categoria "Uso de inscrições" foram encontrados 12 registros. A seguir, são discutidas as categorias encontradas.

\section{Habilidades Relacionadas ao Uso de Inscrições}

$\mathrm{Na}$ época em que foram publicados, os PCNEM fizeram com que os termos competências e habilidades se difundissem nos meios educacionais. De fato, um dos seus objetivos é orientar a mudança de um ensino centrado no conteúdo para o ensino centrado no desenvolvimento de competências e habilidades por parte do aluno. Assim, grande parte das recomendações nele encontradas explicita quais tipos de habilidades os alunos deveriam desenvolver, assim como as justifica. Cientes da importância das representações visuais materiais para as ciências, os autores não deixaram de fora o desenvolvimento de habilidades relacionadas ao uso de inscrições.

Os conceitos de competências e habilidades variam de autor para autor, mas pode-se considerar que o conceito de habilidade envolve o poder de lançar mão de conhecimentos e recursos variados para, em determinada situação, solucionar um problema de caráter prático ou teórico, enquanto competência engloba o uso de diversas habilidades e conhecimentos, de modo criativo

Tabela 1: Números das unidades de registro nos PCNEM

\begin{tabular}{lccccc}
\hline Documentos & gráfic' & símbol' & representaç' & visual' $^{\prime}$ & image' $^{\prime}$ \\
\hline Parte I-Bases Legais & 6 & 0 & 0 & 0 & 0 \\
Parte III - Ciências & 18 & 3 & 12 & 2 & 5 \\
\hline
\end{tabular}


e inovador, em momento apropriado, ou seja, tem um caráter mais amplo (Garcia, 2005). Assim, apresentar competências e habilidades em relação ao uso de inscrições indica o poder de conseguir acessar e recuperar a intenção interpretativa da inscrição a partir das suas características (perspectivas, pontos, linhas, símbolos), utilizando tais sentidos recuperados para construir reflexões, interpretar fenômenos, deduzir tendências e relações, resolver problemas ou, até mesmo, construir outras inscrições.

Na Parte III dos PCNEM, existe, de forma explícita, a indicação das seguintes habilidades e competências, algumas idênticas às encontradas nas Bases Legais:

Interpretar e utilizar diferentes formas de representação (tabelas, gráficos, expressões, ícones...). [...] Identificar, analisar e aplicar conhecimentos sobre valores de variáveis, representados em gráficos, diagramas ou expressões algébricas, realizando previsão de tendências, extrapolações e interpolações e interpretações (Brasil, 1999b, p. 12, grifo nosso).

[...] Compreender os códigos e símbolos próprios da Química atual. [...] Traduzir a linguagem discursiva em outras linguagens usadas em Química: gráficos, tabelas e relações matemáticas (Brasil, 1999b, p. 39, grifo nosso).

[...] reconhecer representações equivalentes de um mesmo conceito, relacionando procedimentos associados às diferentes representações (Brasil, 1999b, p. 42, grifo nosso).

A leitura completa do documento revelou que este trata ainda de outras competências e habilidades, que se vinculam ao letramento gráfico. Como, na categoria "representação e comunicação": "desenvolver modelos explicativos para sistemas tecnológicos e naturais; interpretar e criticar resultados a partir de experimentos e demonstrações" (Brasil, 1999b, p. 12).

Para Roth et al. (2005), a familiaridade e conhecimentos prévios do indivíduo com o tema, assim como o envolvimento anterior em práticas de inscrições que colocam em evidência atividades de leitura, interpretação, transformação e criação de inscrições determinam, em segunda instância, a facilidade ou dificuldade que os alunos terão em interpretar uma inscrição presente, por exemplo, em um livro didático, ou projetada em uma aula. A primeira instância se refere às características visuais da inscrição. Atividades como a criação de modelos, sistematização de informações e discussão de resultados experimentais representam muito mais do que apenas a exposição dos estudantes às inscrições, mas elevam o nível de letramento gráfico de modo que os alunos mudam o foco da compreensão da inscrição para a compreensão do fenômeno a partir da inscrição.

\section{Uso de Inscrições}

Junto às recomendações de habilidades e competências que os alunos devem desenvolver, trazidas pelos PCNEM, estão alguns exemplos de uso de inscrições que o professor pode realizar na sua sala de aula, que elencam a categoria menos recorrente no documento. Esta categoria foi claramente identificada principalmente a partir da unidade de registro gráfic', tanto na Parte I como na Parte III dos PCNEM, mas também pelas unidades de registro representaç' e image'.

Os valores nominais de tensão ou potência dos aparelhos elétricos, [...] os sistemas de representação de mapas e plantas [...], gráficos de dados meteorológicos são exemplos desses códigos presentes no dia-a-dia e cujo reconhecimento e leitura requerem um determinado tipo de aprendizado (Brasil, 1999b, p. 26, grifo nosso).

Determinados aspectos exigem imagens e, mais vantajosamente, imagens dinâmicas; outros necessitam de cálculos ou de tabelas de gráfico; outros podem demandar expressões analíticas, sendo sempre vantajosa a redundância de meios para garantir confiabilidade de registro elou reforço no aprendizado (Brasil, 1999b, p. 53, grifo nosso).

Objetivo semelhante pode ser alcançado se a eleição do grêmio estudantil for uma oportunidade para conhecer melhor os sistemas políticos, ou para entender como a Matemática traduz a tendência de voto por meio de um gráfico de barras, ou para discutir questões éticas relacionadas à prática eleitoral (Brasil, 1999a, p. 81, grifo nosso).

Apesar da pouca recorrência das unidades de registros na Parte I, o último trecho é importante pois coloca a contextualização em destaque. Sequências de ensino contextualizadas, assim como interdisciplinares, aumentam as chances de aprimoramento dos conhecimentos sobre as diversas formas de representações, além de acentuarem a familiaridade e as experiências dos alunos com as inscrições em outras áreas diferentes das ciências naturais, diminuindo dificuldades de leitura e interpretação de inscrições.

\section{Letramento Gráfico na Seção "Relatos de Sala de Aula" da QNEsc}

Conforme mencionado anteriormente, com o intuito de obtermos indícios sobre a presença de práticas de inscrições e o desenvolvimento do letramento gráfico nas salas de aulas de química do nosso país, pesquisamos na seção "Relatos de Sala de Aula" da revista QNEsc, desde o seu início, em 1995, 
até 2017, os trabalhos que mencionam o uso de inscrições nas SD aplicadas nas experiências relatadas. Foram publicados 33 trabalhos, de um total de 129 , que indicam o uso de práticas de inscrições, sendo que entre esses, cinco estavam presentes nas duas categorias que emergiram a partir da leitura completa desses artigos:

(i) Produção de inscrições, a qual contém os artigos cuja aplicação da SD inclui alguma etapa em que os alunos precisavam produzir inscrições;

(ii) Uso direto de inscrições, a qual contém os artigos cuja aplicação da SD inclui alguma etapa em que os professores forneciam inscrições para utilização por parte dos alunos.

\section{Produção de Inscrições}

O Quadro 1 apresenta as referências, em ordem cronológica, dos 18 artigos presentes na primeira categoria e numeração que será seguida para referenciá-los durante a discussão.

Dentre os artigos da categoria "Produção de inscrições", a maioria solicitou a produção de desenhos icônicos ou esquemáticos pelos alunos. Alguns artigos ainda não especificavam se o desenho solicitado deveria ser icônico ou esquemático. A diferença entre esses é que os ícones se assemelham mais do que os esquemas com o fenômeno que representam, o que pode requerer o uso de legendas internas nos esquemas, para restringir as possibilidades interpretativas da inscrição. Esses tipos de inscrições são muito úteis para representar átomos, moléculas, radiação eletromagnética, entre outros, próprios ao mundo cientificamente concebido, como ocorreu no artigo 13, o qual foi o único a especificar o tipo de desenho a ser produzido, sendo solicitado um esquema. As demais SD deixaram essa escolha em aberto. Relações entre

Quadro 1: Artigos da categoria "Produção de inscrições" (QNEsc, 1995-2017), em ordem cronológica

\section{Categoria "Produção de inscrições"}

CASTILHO, D. L.; SILVEIRA, K. T. e MACHADO, A. H. As aulas de química como espaço de investigação e reflexão. Química Nova na Escola, v. 9, p. 14-17, 1999.

FERREIRA, R. M. H.; LOGUERCIO, R. C.; SAMRSLA, V. E. E. e DEL PINO, J. C. Camisinha na sala de aula: saúde, sexualidade e construção de conhecimentos a partir de testes de qualidade. Química Nova na Escola, v. 13, p. 9-12, 2001.

3 MARIA, L. C. S.; LEITE, M. C. A. M.; AGUIAR, M. R. M. P.; OLIVEIRA, R. O.; ARCANJO, M. E. e CARVALHO, E. L. Coleta seletiva separação de plásticos. Química Nova na Escola, v. 17, p. 32-35, 2003.

4 SILVA, R. M. G. Contextualizando aprendizagens em química na formação escolar. Química Nova na Escola, v. 18, p. 26-30, 2003.

5 LOURENÇO, I. M. B. e RIBEIRO, E. M. F. Um plano de ensino para mol. Química Nova na Escola, v. 18, p. 22-25, 2003.

$6 \mathrm{ROCHA}$, J. R. C. e CAVICCHIOLI, A. Uma abordagem alternativa para o aprendizado dos conceitos de átomo, molécula, elemento 6 químico, substância simples e substância composta, nos ensinos fundamental e médio. Química Nova na Escola, v. 21, p. 29-33, 2005.

7 CURI, D. Polímeros e interações moleculares. Química Nova na Escola, v. 23, p. 19-22, 2006.

8 SANJUAN, M. E. C.; SANTOS, C. V. D.; MAIA, J. D. O.; SILVA, A. F. D. e WARTHA, E. J. Maresia: uma proposta para o ensino de eletroquímica. Química Nova na Escola, v. 31, n. 3, p. 190-197, 2009.

SILVA, D. R. e DEL PINO, J. C. Um estudo do processo digestivo como estratégia para a construção de conceitos fundamentais em ciências. Química Nova na Escola, v. 31, n. 4, p. 257-264, 2009.

10 RESENDE, D. R.; CASTRO, R. D. e PINHEIRO, P. C. O saber popular nas aulas de química: relato de experiência envolvendo a produção do vinho de laranja e sua interpretação no ensino médio. Química Nova na Escola, v. 32, n. 3, p. 151-160, 2010.

11 RIBEIRO, E. M. F.; MAIA, J. O. e WARTHA, E. J. As questões ambientais e a química dos sabões e detergentes. Química Nova na Escola, v. 32, n. 3, p. 169-175, 2010.

12 SCAFI, S. H. F. e BIAJONE, J. Desafio militar: missão dada é missão cumprida. Contextualização e interdisciplinaridade na educação química. Química Nova na Escola, v. 33, n. 3, p. 168-177, 2011.

13 LACERDA, C. C.; CAMPOS, A. F. e MARCELINO-JR., C. A. C. Abordagem dos conceitos mistura, substância simples, substância composta e elemento químico numa perspectiva de ensino por situação-problema. Química Nova na Escola, v. 34, n. 2, p. 75-82, 2012.

14 MENDONÇA, M. F. C.; PAIVA, P. T.; MENDES, T. R.; BARRO, M. R.; CORDEIRO, M. R. e KIILL, K. B. A água da fonte natural: sequência 14 de atividades envolvendo os conceitos de substância e mistura. Química Nova na Escola, v. 36, n. 2, p. 108-118, 2014.

15 ROSA, M. F.; SILVA, P. e GALVAN, F. B. A ciência forense no ensino de química por meio da experimentação. Química Nova na Escola, v. 37, n. 1, p. 35-43, 2015.

16 SILVA, N. S.; FERREIRA, A. C. e SILVEIRA, K. P. Ensino de modelos para o átomo por meio de recursos multimídia em uma abordagem investigativa. Química Nova na Escola, v. 38, n. 2, p. 141-148, 2016.

17 BARRETO, B. S. J.; BATISTA, C. H. e CRUZ, M. C. P. Células eletroquímicas, cotidiano e concepções dos educandos. Química Nova na Escola, v. 39, n. 1, p. 52-58, 2017.

18 OLIVEIRA, B. R. M.; KIOURANIS, N. M. M.; EICHLER, M. L. e QUEIROZ, S. L. Chocoquímica: construindo conhecimentos acerca do chocolate por meio do método de aprendizagem cooperativa jigsaw. Química Nova na Escola, v. 39, n. 3, p. 277-285, 2017. 
as solicitações das inscrições e os objetivos almejados com isso estão ilustradas no Quadro 2.

Conforme ilustra o Quadro 2, as inscrições foram solicitadas com as seguintes finalidades: identificação dos conhecimentos prévios ou obtidos a partir da aplicação da SD; apresentação de dados extraídos a partir da realização de experimentos; e desenvolvimento de algum conteúdo na SD. Em relação à primeira finalidade, citamos o artigo 14 , no qual os alunos desenharam como eles imaginavam o caminho que a água percorria, desde a sua fonte até a torneira das suas casas. A partir desses esquemas os autores concluíram que estes reconheciam a existência de um processo de tratamento de água, para torná-la potável e própria para consumo, porém desconheciam as suas etapas. Como, por exemplo, na Figura 1, onde o aluno desenhou três etapas do processo, porém sem denominá-las de maneira mais específica.

Os alunos ainda foram solicitados a representar uma água potável e uma água não potável. A análise dos desenhos indica que estes estavam apegados a aspectos visualmente perceptíveis, como a cor da água. Ou seja, as informações fornecidas apresentavam muitas características do "senso comum" (Mendonça et al., 2014, p. 114). A partir da identificação dessas concepções prévias foi possível realizar a intervenção didática e o desenvolvimento de conceitos, como potabilidade, pureza, pH, substância e mistura, assim como apresentar as etapas dos processos de tratamento da água. Ao serem requisitados a esquematizarem novamente as representações mencionadas, os autores notaram que ocorreu mudança conceitual, já que

Quadro 2: Inscrições nos artigos da categoria "Produção de inscrições" e os objetivos com que foram empregadas

\begin{tabular}{|c|c|c|}
\hline Artigo & Inscrições Solicitadas aos Alunos & Objetivo \\
\hline 1 & $\begin{array}{l}\text { Representação por meio de desenhos do comportamento do ar } \\
\text { dentro de um tubo com um balão na boca antes e depois de ser } \\
\text { aquecido. }\end{array}$ & $\begin{array}{l}\text { Identificação de conhecimentos prévios referentes aos conteúdos } \\
\text { abordados na SD. }\end{array}$ \\
\hline 2 & Tabelas com propriedades de preservativos. & Apresentação de dados obtidos em etapa experimental na SD. \\
\hline 3 & Tabela com observações de teste da chama com plásticos. & Apresentação de dados obtidos em etapa experimental na SD. \\
\hline 4 & Representação do ciclo da água, por meio de desenhos. & $\begin{array}{l}\text { Identificação de conhecimentos prévios referentes aos conteúdos } \\
\text { abordados na SD. }\end{array}$ \\
\hline 5 & $\begin{array}{l}\text { Gráfico que mostrasse relação proporcional entre a massa e o } \\
\text { número de objetos. }\end{array}$ & Desenvolvimento de conteúdos abordados na SD. \\
\hline 6 & $\begin{array}{l}\text { Representação de substâncias químicas, por meio de desenhos } \\
\text { esquemáticos. }\end{array}$ & Desenvolvimento de conteúdos abordados na SD. \\
\hline 7 & $\begin{array}{l}\text { Tabela com resultados de atividades experimentais sobre } \\
\text { polímeros. }\end{array}$ & Apresentação de dados obtidos em etapa experimental na SD. \\
\hline 9 & Tabela de solubilidade. & $\begin{array}{l}\text { Identificação de conhecimentos prévios referentes aos conteúdos } \\
\text { abordados na SD. }\end{array}$ \\
\hline 10 & $\begin{array}{l}\text { Representação, por meio de desenhos, que explicassem a origem } \\
\text { do álcool no vinho de laranja e a interação do açúcar com a água } \\
\text { quente e fria. }\end{array}$ & $\begin{array}{l}\text { Identificação de conhecimentos obtidos pelos alunos com a } \\
\text { aplicação da SD. }\end{array}$ \\
\hline 11 & $\begin{array}{l}\text { Gráfico que mostrasse a variação de oxigênio dissolvido ao longo } \\
\text { de um rio. }\end{array}$ & Apresentação de dados obtidos em etapa experimental na SD. \\
\hline 12 & Esboço de um circuito elétrico, por meio de desenho esquemático. & Desenvolvimento de conteúdos abordados na SD. \\
\hline 13 & $\begin{array}{l}\text { Representação de substâncias químicas, por meio de desenhos } \\
\text { esquemáticos. }\end{array}$ & Desenvolvimento de conteúdos abordados na SD. \\
\hline 17 & $\begin{array}{l}\text { Representações de células eletroquímicas, por meio de desenhos } \\
\text { esquemáticos. }\end{array}$ & $\begin{array}{l}\text { Identificação de conhecimentos obtidos pelos alunos com a } \\
\text { aplicação da SD. }\end{array}$ \\
\hline 18 & Tabela com informações acerca do chocolate. & Desenvolvimento de conteúdos abordados na SD. \\
\hline
\end{tabular}




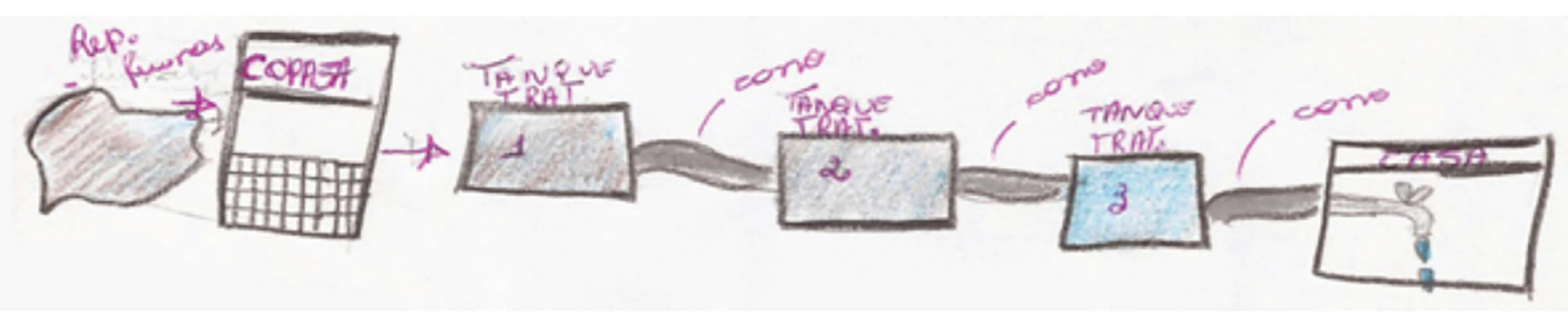

Figura 1: Desenho de um aluno representando o trajeto da água da estação de tratamento até as residências. Fonte: Mendonça et al. (2014).

os aspectos elencados, agora, estavam associados à visão atômico-molecular.

Nessa perspectiva, os autores do artigo 16 sugerem ainda que, além de apresentar o desenho, os alunos descrevam e expliquem o seu teor, assim o professor terá mais ferramentas para avaliar as representações produzidas por eles.

Em relação à segunda finalidade, citamos o artigo 7, no qual foram propostos três experimentos para a discussão das propriedades de diferentes materiais em função de suas estruturas e interações moleculares. Como uma das etapas do experimento, os alunos são incentivados a anotar os resultados observados em tabelas. Os autores ainda afirmam que mesmo não necessitando de laboratório e aparato sofisticado, atividades experimentais desenvolvem habilidades importantes, entre elas a construção de tabelas. Adicionamos ainda a essa habilidade a construção de outros tipos de inscrições e a transformação de uma inscrição em outra, como por exemplo, de uma tabela em um gráfico (Roth et al., 2005).

Em relação à terceira finalidade, citamos o artigo 18 , no qual os alunos analisaram rótulos de diferentes tipos de chocolate (ao leite, diet, branco e amargo) e elencaram seus ingredientes e suas informações nutricionais em uma tabela, tendo em vista o desenvolvimento dos conteúdos abordados, a partir do estabelecimento de componentes comuns entre eles.

Os artigos 5 e 11 foram os únicos a solicitar como inscrição um gráfico. No primeiro não é especificado o tipo de gráfico a ser construído, enquanto que no segundo foi produzido um gráfico de linha. No artigo 11, após entender sobre a composição, fabricação e ação do sabão e detergente, os alunos realizaram um procedimento simples para determinação do oxigênio dissolvido em amostras de água do Rio Cachoeira, em Ilhéus - BA. Os resultados expressos em gráfico foram discutidos em sala de aula, causando um impacto, pois os alunos perceberam a sua responsabilidade com o meio-ambiente, já que este evidenciou que o oxigênio dissolvido caía significativamente ao atravessar o centro urbano.

A solicitação de produção de gráficos em apenas dois artigos é preocupante já que estes são uma forma de inscrição encontrada em espaços distintos, além do científico, em diversas formas (linha, barra, pizza etc.), assim como por estarem em destaque nos PCNEM, como mostrado anteriormente. Esse tipo de inscrição está ainda bastante vinculado ao ensino de matemática em detrimento do ensino de ciências. Ademais, a pouca recorrência do tratamento da questão do letramento gráfico em cursos de formação de professores de química, provavelmente, colaborou para o alcance de tal panorama. Os gráficos ainda são, como apontam Roth et al. (2005), inscrições com as quais os alunos mais têm dificuldades de leituras e interpretação. No entanto, isso não advém, necessariamente, de más concepções ou de deficiências de aprendizagem, mas, segundo os autores, e corroborando com os resultados encontrados aqui, da escassez de atividades que os colocam em contato com os gráficos a partir de exercícios de criação, leitura, interpretação e discussão dos aspectos e relações inerentes a eles.

\section{Uso Direto de Inscrições}

O Quadro 3 apresenta as referências, em ordem cronológica, dos 20 artigos presentes na segunda categoria e numeração que será seguida para referenciá-los durante a discussão. Os artigos que já estavam presentes na primeira categoria continuam com a numeração apresentada anteriormente, indicada entre parênteses.

Dentre os artigos da categoria "Uso direto de inscrições", foi possível identificar o emprego dos mesmos tipos de inscrições da categoria anterior, além de mapas. Relações entre a utilização de inscrições e os objetivos almejados com isso estão ilustradas no Quadro 4.

Conforme ilustra o Quadro 4, as inscrições foram utilizadas com duas finalidades: introdução da temática e discussão do conteúdo abordado na SD. Em relação à primeira finalidade, citamos o artigo 21, que traz uma SD abordando a mineralogia como um assunto articulador de uma proposta curricular para o ensino de química na educação básica e fez uso de fotografias de paisagens de regiões montanhosas e vulcânicas, como a Figura 2, que representa um gêiser.

Os autores selecionaram imagens com cores vívidas e ressaltaram o seu aspecto motivacional e a possibilidade que oferecem de articulação com questões sociais presentes no processo de exploração de minerais, como é o caso de uma foto de um trabalhador colhendo enxofre na borda do vulcão Kawah Ijen, na Indonésia, exposto a vapores tóxicos e ácidos.

O uso de fotografias com o mesmo propósito motivacional dos autores do artigo 21 ocorre nos artigos 14, 15, 23, 26, 29 e 32. Não é surpreendente tal constatação, especialmente no momento de introdução do conteúdo, pois segundo Roth et al. (2005), esse tipo de inscrição está mais propenso a causar um impacto sobre os indivíduos do que os gráficos ou equações. A 
Quadro 3: Artigos da categoria “Uso direto de inscrições” (QNEsc, 1995-2017), em ordem cronológica

Categoria "Uso direto de inscrições"

(2) FERREIRA, R. M. H.; LOGUERCIO, R. C.; SAMRSLA, V. E. E. e DEL PINO, J. C. Camisinha na sala de aula: saúde, sexualidade e construção de conhecimentos a partir de testes de qualidade. Química Nova na Escola, v. 13, p. 9-12, 2001.

CORREIA, P. R. M.; DAZZANI, M.; MARCONDES, M. E. R. e TORRES, B. B. A bioquímica como ferramenta interdisciplinar: vencendo o desafio da integração de conteúdos no ensino médio. Química Nova na Escola, v. 19, p. 19-23, 2004.

20

NERI, A. L. P.; LIEGEL, R. M. e FERNANDEZ, C. Reações envolvendo íons em solução aquosa: uma abordagem problematizadora para a previsão e equacionamento de alguns tipos de reações inorgânicas. Química Nova na Escola, v. 23, p. 14-18, 2006.

21 SAMRSLA, V. E. E.; GUTERRES, J. D. O.; EICHLER, M. L. e DEL PINO, J. C. Da mineralogia à química: uma proposta curricular para o primeiro ano do ensino médio. Química Nova na Escola, n. 25, p. 20-26, 2007. n. 1, p. 31-33, 2009.

(8)

SANJUAN, M. E. C.; SANTOS, C. V. D.; MAIA, J. D. O.; SILVA, A. F. D. e WARTHA, E. J. Maresia: uma proposta para o ensino de eletroquímica. Química Nova na Escola, v. 31, n. 3, p. 190-197, 2009.

CAVALCANTI, J. A.; FREITAS, J. D.; MELO, A. D. e FREITAS FILHO, J. D. Agrotóxicos: uma temática para o ensino de química. Química Nova na Escola, v. 32, n. 1, p. 31-36, 2010.

RUA, E. R. e SOUZA, P. S. A. Educação ambiental em uma abordagem interdisciplinar e contextualizada por meio das disciplinas química e estudos regionais. Química Nova na Escola, v. 32, n. 2, p. 95-100, 2010.

SOUZA, F. L. e MARTINS, P. Ciência e tecnologia na escola: desenvolvendo cidadania por meio do projeto "biogás - energia renovável para o futuro". Química Nova na Escola, v. 33, n. 1, p. 19-24, 2011

SCAFI, S. H. F. e BIAJONE, J. Desafio militar: missão dada é missão cumprida. Contextualização e interdisciplinaridade na educação química. Química Nova na Escola, v. 33, n. 3, p. 168-177, 2011.

26 FRAGAL, V. H.; MAEDA, S. M.; PALMA, E. D.; RODRIGUES, M.; BUZATTO, M. e SILVA, E. L. Uma proposta alternativa para o ensino de eletroquímica sobre a reatividade de metais. Química Nova na Escola, v. 33, n. 4, p. 216-222, 2011.

27 SILVA, S. C. e ABREU, D. G. Aulas coletivas na escola pública: interação entre universidade-escola. Química Nova na Escola, v. 34, n. 3, p. 131-135, 2012.

SATURNINO, J. C. S. F.; LUDVIDO, I. e SANTOS, L. J. Pôquer dos elementos dos blocos s e p. Química Nova na Escola, v. 35, n. 3, p. 174-181, 2013.

(14)

MENDONÇA, M. F. C.; PAIVA, P. T.; MENDES, T. R.; BARRO, M. R.; CORDEIRO, M. R. e KIILL, K. B. A água da fonte natural: sequência de atividades envolvendo os conceitos de substância e mistura. Química Nova na Escola, v. 36, n. 2, p. 108-118, 2014.

SOUZA, G. P.; PEREIRA, A. I.; SILVA, C. M.; GANDRA, D. A.; OLIVEIRA, G. P.; RAMOS, G. R.; CASELA, I.; FERNANDES, J. M.; SENA, M. C. C.; MARTINS, M. R.; NASCIMENTO, M. O.; FIDELES, R. A.; RAMOS, S. N. C.; ARAÚJO, T. D.; MOREIRA, L. M. Imagens, analogias, modelos e charge: distintas abordagens no ensino de química envolvendo o tema polímeros. Química Nova na Escola, v. 36, n. 3, p. 200-210, 2014.

(15) ROSA, M. F.; SILVA, P. e GALVAN, F. B. A ciência forense no ensino de química por meio da experimentação. Química Nova na Escola, v. 37, n. 1, p. 35-43, 2015.

SOUZA, P. V. T.; SILVA, M. D.; AMAURO, N. Q.; MORI, R. C. e MOREIRA, P. F. S. D. Densidade: uma proposta de aula investigativa. Química Nova na Escola, v. 37, n. 2, p. 120-124, 2015.

31 OLIVEIRA, J. S.; SOARES, M. H. F. B. e VAZ, W. F. Banco químico: um jogo de tabuleiro, cartas, dados, compras e vendas para o ensino do conceito de soluções. Química Nova na Escola, v. 37, n. 4, p. 285-293, 2015.

32 SILVA, M. A. N. e QUADROS, A. L. Ensino por temas: a qualidade do ar auxiliando na construção de significados em química. Química Nova na Escola, v. 38, n. 1, p. 40-46, 2016.

CRUZ, A. A. C.; RIBEIRO, V. G.; LONGHINOTTI, E. e MAZZETTO, S. E. A ciência forense no ensino de química por meio da experimentação investigativa e lúdica. Química Nova na Escola, v. 38, n. 2, p. 167-172, 2016.

única SD na qual as fotografias não tiveram o referido objetivo foi descrita no artigo 28, situação em que elas ilustraram as cartas do jogo didático "Pôquer dos Elementos dos Blocos s e p" usado no ensino de tabela periódica e periodicidade para alunos do ensino médio.

Em relação à segunda finalidade, esta foi levada a cabo fazendo uso de todos os tipos de inscrições identificadas nesta categoria, inclusive a fotografia, que conforme mencionado, surgiu apenas uma vez, sem caráter introdutório, nas cartas do referido jogo. Assim como na categoria anterior, a qual abarca artigos onde existe a solicitação de produção da inscrição por parte dos alunos, o uso de gráficos foi pouco frequente. De 
Quadro 4: Inscrições nos artigos da categoria "Uso direto de inscrição" e os objetivos com que foram empregadas

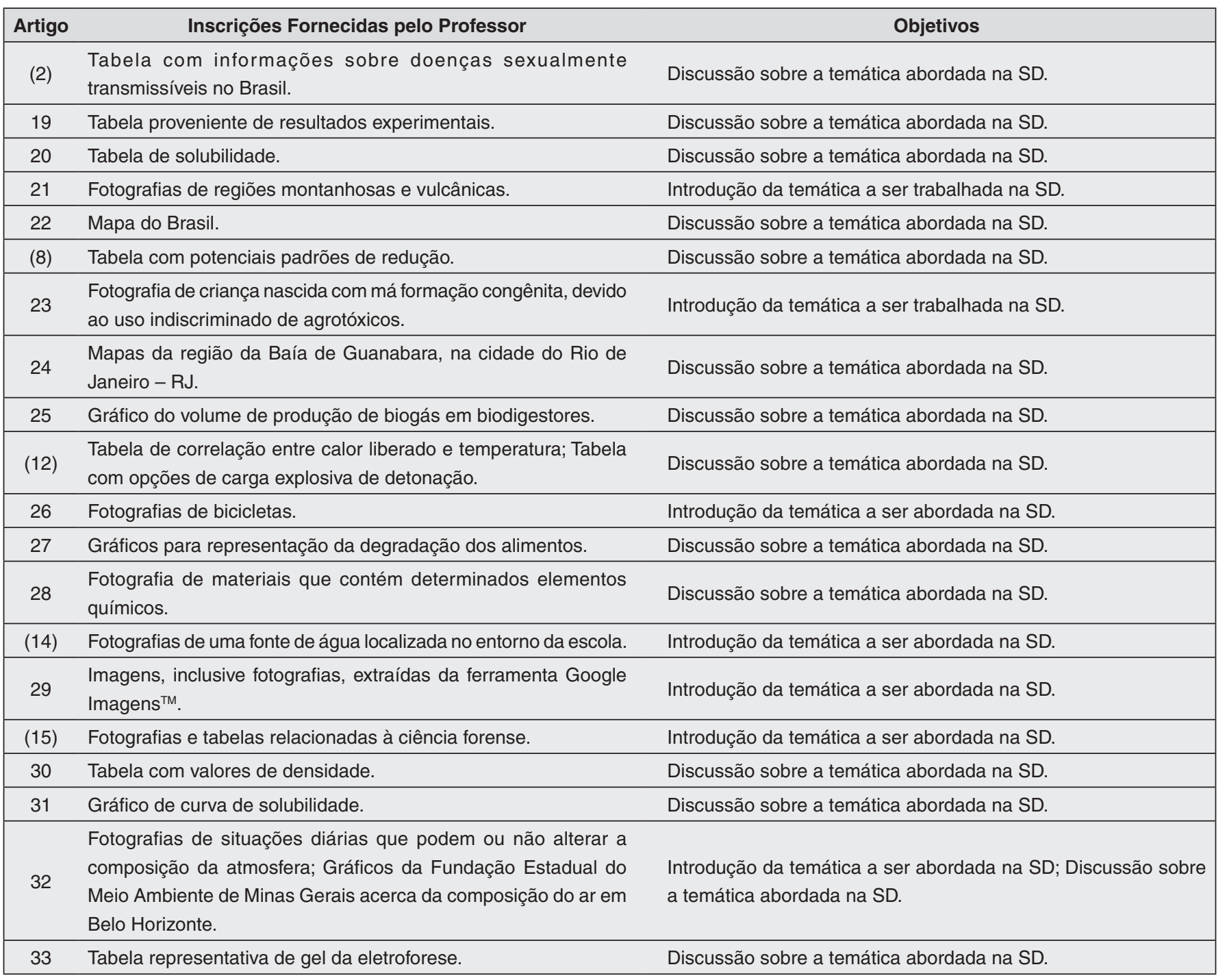

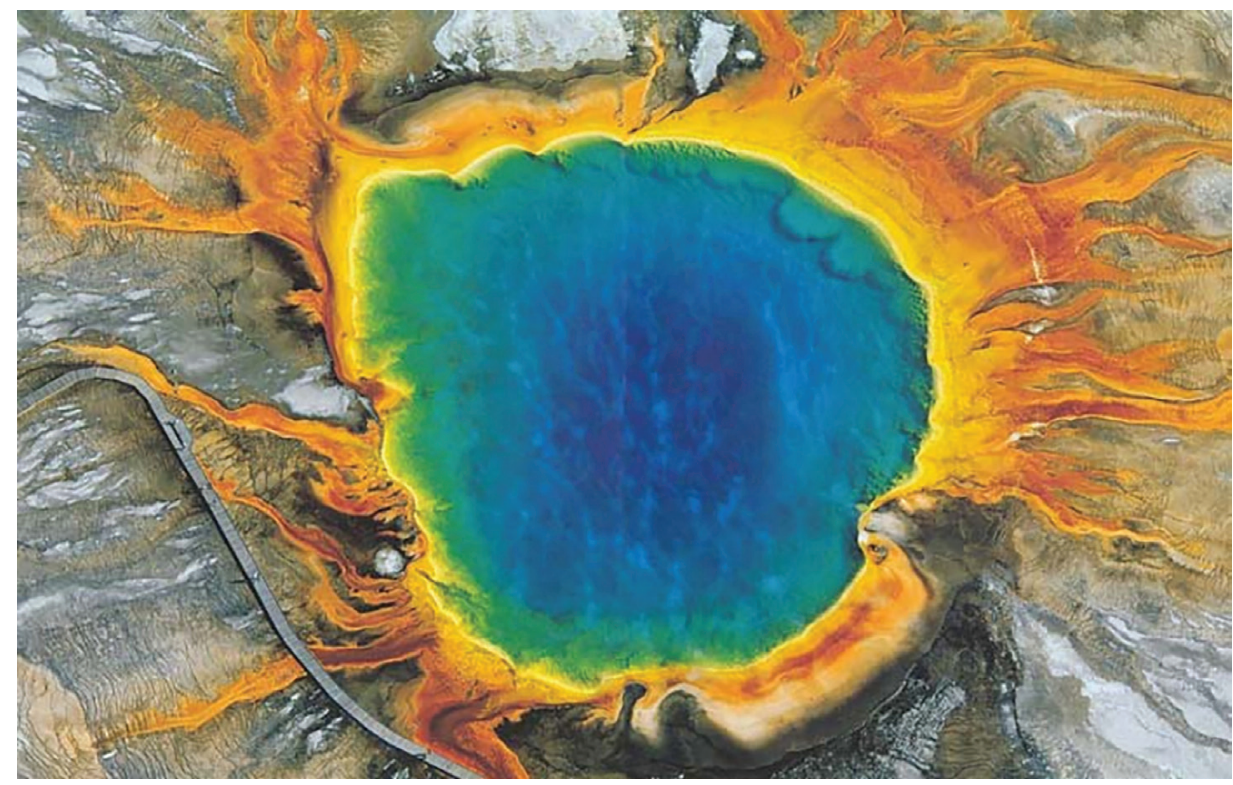

Figura 2: Fotografia de gêiser no Parque Yellowstone, nos Estados Unidos da América. Fonte: Samrsla et al. (2007). 
fato, os professores forneceram gráficos aos estudantes apenas nas SD dos artigos 25, 27, 31 e 32. Com exceção do artigo 31, que não menciona o tipo de gráfico utilizado, os demais são gráficos de linha.

No artigo 32, por exemplo, no qual a SD proposta visou o desenvolvimento de conteúdos acerca da química da atmosfera e dos fatores que alteram a qualidade do ar, os gráficos eram de monitoramento de concentrações de gases da atmosfera na região de Belo Horizonte - MG. O debate dessas inscrições inseriu os alunos numa perspectiva crítica e de autorresponsabilidade na identificação de problemas ambientais e sociais. Esse tipo de situação dá utilidade ao conhecimento apresentado na inscrição e assim conquista a confiança do aluno, proporcionando um contínuo amadurecimento do seu letramento gráfico (Nass, 2008).

O uso de tabelas foi o mais frequente nesta categoria, sempre com o objetivo de fomentar a discussão de conteúdos relacionados às temáticas abordadas nas SD. Destacamos o artigo 8, que solicita tanto a construção das mesmas, o que justifica a sua presença no Quadro 2, quanto o seu uso direto, apontado no Quadro 4. Os alunos inicialmente foram requisitados a organizar, com base no observado em atividade experimental, uma tabela que ordenava a reatividade de metais perante uma solução ácida. Em seguida, tal escala foi comparada com uma tabela de potenciais de redução padrão de metais que foi fornecida pelo professor. Dessa forma, os alunos puderam relacionar os dados experimentais obtidos com dados teóricos, o que representa uma das etapas do fazer científico.

Nessa perspectiva, a proposta corrobora a noção de atividades experimentais como uma prática autêntica para o desenvolvimento de letramento gráfico, não apenas por meio da solicitação de inscrições, mas também a partir do uso destas, já que os alunos podem confrontar os dados obtidos com os presentes na literatura, na forma de gráficos, histogramas, tabelas etc. Os autores do artigo 8 ainda citam que simplesmente apresentar uma tabela de potenciais padrão de redução de metais não privilegia o desenvolvimento cognitivo do aluno, tendo sido necessário utilizar uma abordagem que relacionasse os três aspectos do conhecimento químico: macroscópico, microscópico e simbólico. É nesse último aspecto que as inscrições se inserem, sendo desejável, portanto, que o professor assimile o papel das mesmas na sala de aula, assim como as suas potencialidades para aprimorar o entendimento do que está sendo estudado pelo aluno.

O uso de mapas foi observado apenas nos artigos 22 e 24 . No artigo 22, o mapa do Brasil estilizado (Figura 3) é apresentado com o intuito de motivar os alunos ao estudo dos elementos químicos e da tabela periódica. No artigo 24, a SD, aplicada

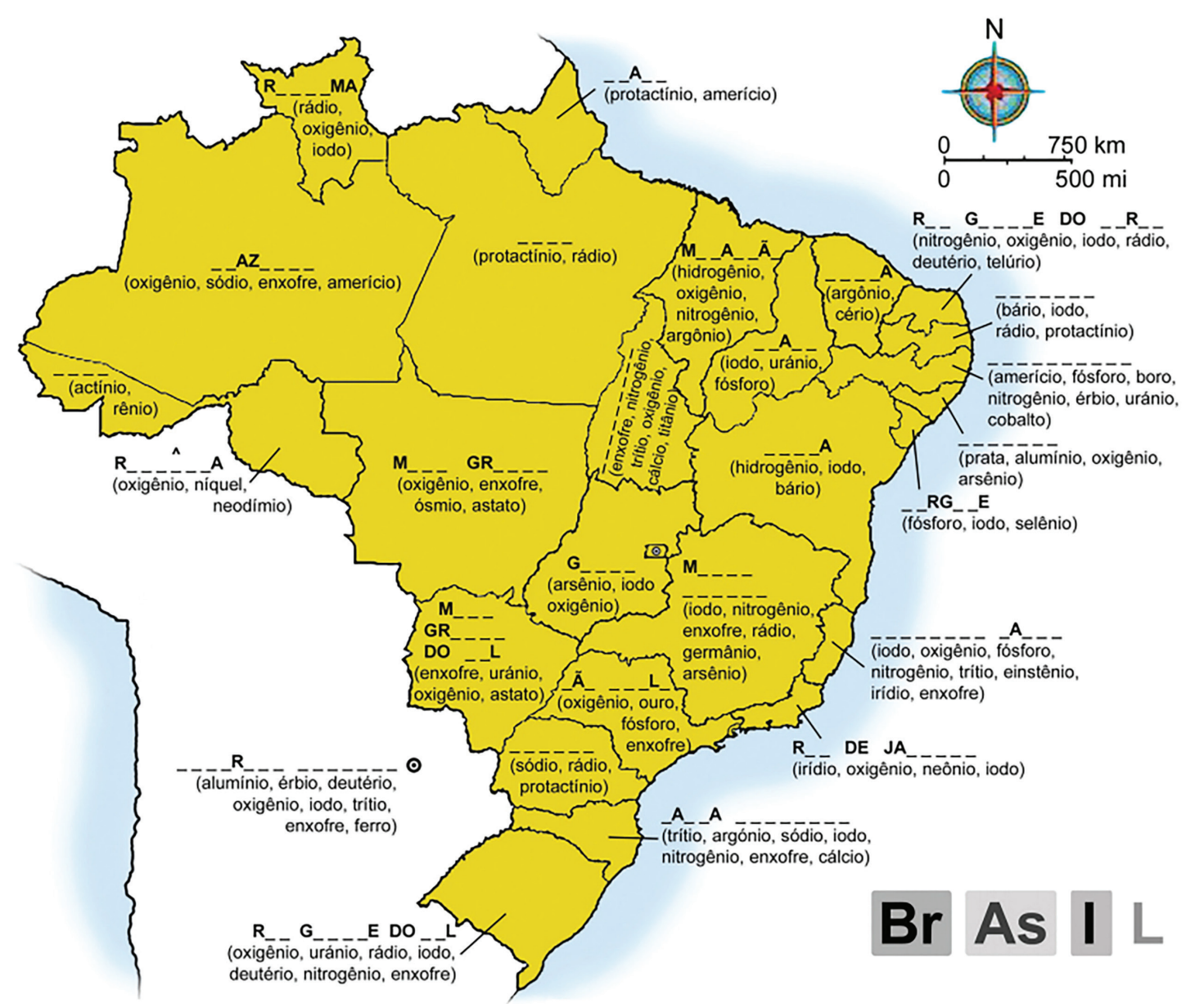

Figura 3: Mapa do Brasil. Fonte: Franco-Mariscal e Cano-Iglesias (2009). 
com apoio de um weblog, propiciou investigação da degradação do ecossistema da Baía de Guanabara - RJ.

Diferentemente do que foi afirmado com relação aos gráficos, a pouca recorrência de mapas nas SD não é surpreendente, uma vez que estes não se constituem em dispositivos gráficos frequentes no ensino de ciências, sendo escassos mesmo em livros didáticos (Gillespie, 1993).

\section{Considerações Finais}

Mesmo com origens ainda na década de 1990, os PCNEM possuem importância no cenário da educação nacional, pois continuam sendo discutidos em textos que versam sobre o assunto e em cursos de formação de professores. O fato de chamarem atenção para a necessidade de desenvolvimento por parte dos alunos de habilidades relacionadas ao uso de inscrições, e de também apresentarem exemplos de situações nas quais estas podem ser empregadas no ensino de ciências, sinaliza a relevância da promoção do letramento gráfico, especialmente em aulas dessa disciplina.

Neste trabalho procuramos indícios sobre a forma como o letramento gráfico vem sendo promovido no ensino de química, tomando por base a natureza das SD presentes nos artigos publicados na seção "Relatos de Sala de Aula" da QNEsc, que divulga experiências didáticas levadas a cabo por professores da área de educação em química. Os resultados alcançados permitem a tessitura das seguintes considerações:

- O conjunto de SD investigadas demonstra possibilidades e objetivos de inclusão de práticas com inscrições na sala de aula de química, seja pela solicitação de produção de inscrições aos alunos ou uso de inscrições fornecidas pelo professor. Este trabalho viabiliza o acesso dos educadores a uma série de artigos, elencados no Quadro 1 e no Quadro 2 , vinculados a essa vertente e, dessa forma, tem o potencial de contribuir para que discussões sistematizadas sobre o letramento gráfico possam ser concretizadas em espaços formativos docentes.

- Apesar das recomendações dos PCNEM, a recorrência do uso de inscrições em ambientes de ensino de química ainda é escassa. De fato, no período investigado, foram publicados 129 artigos na seção em foco e apenas 33 tratam de SD nas quais foi claramente explicitado o trabalho com inscrições. Conforme discutido anteriormente, aprender a utilizar inscrições envolve práticas de aquisição e o acesso a elas precisa ser incrementado nas escolas brasileiras.

- Dentre as inscrições produzidas pelos alunos destacaram-se as tabelas e as representações de fenômenos ou artefatos por meio de desenhos. Nota-se que a requisição de tabelas estava altamente associada à execução de atividades experimentais e à organização do conhecimento, já os desenhos estavam associados a ocasiões nas quais os professores procuravam caracterizar o conhecimento que os estudantes possuíam. Dentre as inscrições oferecidas pelo professor sobressaíram-se as tabelas e as fotografias, especialmente em momentos de apresentação de informações e introdução da temática da SD. Os gráficos, em contraponto, não encontraram espaço considerável em nenhuma das duas situações e o seu emprego foi restrito, praticamente, a um único tipo, o gráfico de linha. Considerando que uma das características marcantes das ciências naturais é a utilização de gráficos como elemento importante na representação das leis da natureza, ampliar e diversificar o seu uso é fundamental.

- Ainda com relação às inscrições manipuladas durante as SD, cabe salientar o uso das fotografias quase exclusivamente com caráter motivacional. Por ser a câmera fotográfica, atualmente, um instrumento de fácil aquisição, as fotografias têm potencialidade para ganhar uma nova dimensão na educação em química, viabilizando a inserção de atividades de observação e descrição de fenômenos em ciências.

- Com relação aos artigos que estavam presentem em ambas as categorias, é notável que as abordagens assumidas nas SD tinham um cunho experimental. Considerando os demais trabalhos com cunho experimental, é possível estabelecer relações entre as inscrições e essas abordagens, denominadas neste texto de abordagens autênticas, com indicativo de que estas abrem espaços tanto para a produção de inscrições como para a utilização das mesmas.

- Outras abordagens que também carreguem em seu bojo tal autenticidade são desejáveis no ensino de química, tais como exposições orais produzidas pelos alunos sobre assuntos que exigem a discussão de inscrições. O processo de elaboração das exposições possibilita avaliações críticas acerca de inscrições a ser inseridas na apresentação, abrindo espaços para que o aluno possa criar suas próprias inscrições ou adaptar as existentes na literatura a fim de torná-las legíveis ao seu público-alvo, usualmente os colegas de sala. Por fim, a discussão das considerações aqui dispostas é extremamente pertinente em cursos de formação docente, para que se difunda a importância da construção, leitura e interpretação de inscrições, entre outras formas de representação do conhecimento científico, nos seus mais diversos níveis.

\section{Referências}

ARAUJO, E. G. O tratamento da informação nas séries iniciais - uma proposta de formação de professores para o ensino de gráficos e tabelas. Dissertação (Mestrado). Universidade Federal de Santa Catarina, Florianópolis, 2008.

BARDIN, L. Análise de conteúdo. $5^{\text {a }}$ ed. Lisboa: Edições 70, 2009.

BRASIL. Ministério da Educação. Base nacional comum curricular. 2017. Disponível em http://basenacionalcomum.mec.gov.br/images/ BNCC_EI_EF_110518_versaofinal_site.pdf, acessado em Maio 2019. Secretaria de Educação Fundamental. Parâmetros curriculares nacionais: $1^{\mathrm{a}}$ a $4^{\mathrm{a}}$ série. Brasília: MEC/SEF, 1997.

Ministério da Educação e do Desporto. Conselho Nacional de Educação. Câmara da Educação Básica. Resolução $n^{\circ}$ 2, de 30 
de janeiro de 2012. Define diretrizes curriculares nacionais para o ensino médio. Brasília: CNE/CEB, 2012.

Secretaria de Educação Média e Tecnológica. Parâmetros curriculares nacionais do ensino médio. Parte I - bases legais. Brasília: MEC/SEMTEC, 1999a.

Parâmetros curriculares nacionais do ensino médio. Parte III - ciências da natureza, matemática e suas tecnologias. Brasília: MEC/SEMTEC, 1999b.

BOWEN, G. M. e ROTH, W. M. Why students may not learn to interpret scientific inscriptions. Research in Science Education, v. 32, n. 3, p. 303-327, 2002.

DANOS, X. Graphicacy within the secondary school curriculum, an exploration of continuity and progression of graphicacy in children aged 11 to 15. Tese (Doutorado). Loughborough University, Loughborough, 2011.

FERREIRA, C. R. e ARROIO, A. Visualizações no ensino de química: concepções de professores em formação inicial. Química Nova na Escola, v. 35, n. 3, p. 199-208, 2013.

FRANCO-MARISCAL, A. J. e CANO-IGLESIAS, M. J. Soletrando o Br-As-I-L com símbolos químicos. Química Nova na Escola, v. 31, n. 1, p. 31-33, 2009.

GARCIA, L. A. M. Competências e habilidades: você sabe lidar com isso? Educação e Ciência On Line. Brasília: Universidade de Brasília, 2005. Disponível em http://miniweb.com.br/Atualidade/ entrevistas/Profa_Lenise/competencias.pdf, acessado em Maio 2019.

GILLESPIE, C. S. Reading graphic displays: what teachers should know. Journal of Reading, v. 36, n. 5, p. 350-354, 1993.

LATOUR, B. e WOOLGAR, S. A vida de laboratório: a produção dos fatos científicos. Rio de Janeiro: Relume Dumará, 1997.

LEMKE, J. Multiplying meaning: visual and verbal semiotics in scientific text. In: MARTIN, J. e VEEL, R. (Eds.). Reading science. Londres: Routledge, 1998, p. 87-113.

LUNSFORD, E.; MELEAR, C. T.; ROTH, W. M.; PERKINS, M. e HICKOK, L. G. Proliferation of inscriptions and transformations among preservice science teachers engaged in authentic science. Journal of Research in Science Teaching, v. 44, n. 4, p. 538-564, 2007.

MENDONÇA, M. F. C.; PAIVA, P. T.; MENDES, T. R.; BARRO, M. R.; CORDEIRO, M. R. e KIILL, K. B. A água da fonte natural: sequência de atividades envolvendo os conceitos de substância e mistura. Química Nova na Escola, v. 36, n. 2, p. 108-118, 2014.
MORAES, R. Análise de conteúdo. Revista Educação, v. 22, n. 37, p. 7-32, 1999

NASS, D. P. Gráficos como representações visuais relevantes no processo ensino-aprendizagem: uma análise de livros didáticos de química do ensino médio. Dissertação (Mestrado). Universidade de São Paulo, São Carlos, 2008.

OLANDE, O. Graphical artefacts: taxonomy of students' response to test items. Educational Studies in Mathematics, v. 85, n. 1, p. 53 74,2014

POZZER, L. L. e ROTH, W. M. Prevalence, function, and structure of photographs in high school biology textbooks. Journal of Research in Science Teaching, v. 40, n. 10, p. 1089-1114, 2003.

QUEIROZ, S. L e VERAS, L. Química nova na escola: contribuições para o desenvolvimento de atividades didáticas. Química Nova na Escola, v. 37, n. esp. 2, p. 133-139, 2015.

ROTH, W. M. Reading graphs: contributions to an integrative concept of literacy. Journal of Curriculum Studies, v. 34, n. 1, p. 1-24, 2002.

e MCGINN, M. K. Inscriptions: toward a theory of representing as social practice. Review of Educational Research, v. 68, n. 1, p. 35-59, 1998.

; POZZER-ARDENGHI, L. e HAN, J. Y. Critical graphicacy: understanding visual representation practices in school science. In: ZEIDLER, D. L. (Ed.). Contemporary trends and issues in science education. New York: Springer, 2005, v. 26.

SAMRSLA, V. E. E.; GUTERRES, J. D. O.; EICHLER, M. L. e DEL PINO, J. C. Da mineralogia à química: uma proposta curricular para o primeiro ano do ensino médio. Química Nova na Escola, v. 25, p. 20-26, 2007.

SILVA, M. B. A construção de inscrições e seu uso no processo argumentativo em uma atividade investigativa de biologia. Tese (Doutorado). Universidade de São Paulo, São Paulo, 2015.

STOKES, S. Visual literacy in teaching and learning: a literature perspective. Electronic Journal for the Integration of Technology in Education, v. 1, n. 1, p. 10-19, 2002.

XAVIER, J. P. Letramento visual crítico: leitura, interpretação e apropriação das imagens dos livros didáticos. Dissertação (Mestrado). Universidade Federal de Minas Gerais, Belo Horizonte, 2015. 